This item was submitted to Loughborough's Research Repository by the author.

Items in Figshare are protected by copyright, with all rights reserved, unless otherwise indicated.

\title{
The environmental effects of peak hour air traffic congestion: the case of London Heathrow Airport
}

PLEASE CITE THE PUBLISHED VERSION

http://dx.doi.org/10.1016/j.retrec.2016.04.012

PUBLISHER

(C) Elsevier

VERSION

AM (Accepted Manuscript)

PUBLISHER STATEMENT

This work is made available according to the conditions of the Creative Commons Attribution-NonCommercialNoDerivatives 4.0 International (CC BY-NC-ND 4.0) licence. Full details of this licence are available at: https://creativecommons.org/licenses/by-nc-nd/4.0/

\section{LICENCE}

CC BY-NC-ND 4.0

\section{REPOSITORY RECORD}

Irvine, Daniel, Lucy Budd, Stephen Ison, and Gareth Kitching. 2019. "The Environmental Effects of Peak Hour Air Traffic Congestion: The Case of London Heathrow Airport”. figshare. https://hdl.handle.net/2134/21965. 


\title{
The environmental effects of peak hour air traffic congestion: the case of London Heathrow Airport
}

\author{
Daniel Irvine ${ }^{1,2}$, Lucy Budd ${ }^{1}$, Stephen Ison ${ }^{1}$, Gareth Kitching ${ }^{2}$ \\ ${ }^{1}$ School of Civil and Building Engineering, Loughborough University, Loughborough, \\ United Kingdom \\ ${ }^{2}$ Aviation Economics, 40 Friar Lane, Nottingham, United Kingdom \\ Corresponding author: Daniel Irvine daniel.irvine@aviationeconomics.com
}

\begin{abstract}
The commercial air transport sector currently faces the serious and seemingly incompatible challenge of meeting growing consumer demand for flight whilst reducing its environmental impact and meeting increasingly stringent international emissions targets. Growing demand for air travel combined with improvements in environmental performance in other industrial sectors means that commercial aviation has become a key focus for tackling climate change. The aim of this paper is to quantify the impacts of capacity-induced airport congestion using the case of London Heathrow Airport. The paper quantifies the environmental effect of airborne delays to inbound aircraft at the heavily constrained London Heathrow Airport on emissions and local air quality. The findings reveal that the additional $\mathrm{CO}_{2}$ and $\mathrm{NO}_{\mathrm{x}}$ emissions resulting from airborne delays are significant and will increase if capacity constraints on the ground are not addressed. The results are analysed in the context of Heathrow's climate change targets and current debates surrounding expansion and the challenge of reconciling environmental sustainability with aviation growth.
\end{abstract}

Keywords: Airport capacity, climate change, air quality, sustainability, UK

\section{Introduction}

Concern about the negative effects of commercial aircraft emissions on local air quality and the global climate remain high on public and political agendas. The air transport industry is committed to reducing its environmental externality effects by developing new more fuelefficient technologies, exploring alternative fuel sources and by adopting more environmentally efficient operating procedures. However, incremental improvements in environmental performance are being offset by rising global consumer demand for flight and the concomitant increase in air traffic movements. The mismatch between growing demand for flights and a limited supply of runway slots is particularly acute in major world cities which have long been the epicentres of global aeronautical activity. The capacity constraints and the economic disbenefits that accrue from current levels of congestion are driving the development of new terminals, runways and airports but this process is highly controversial with the anticipated socio-economic benefits of airport growth juxtaposed against the negative socio-economic and environmental externalities of expansion.

Estimations of aviation's contribution to climate change are complicated by factors such as cloud enhancement and amplification by altitude, which are much less understood than other more general aspects of climate change. Lee et al. (2009) estimate that the contribution of aviation to the global problem of climate change is between $2 \%$ and $14 \%$ (including aviationinduced clouds). There are a number of different ways in which aviation impacts climate 
change, however the largest, most understood and most measurable is $\mathrm{CO}_{2}$, and this will be the focus of this paper in terms of climate change.

In the European Union, aviation-derived $\mathrm{CO}_{2}$ emissions alone have risen $110 \%$ between 1990 and 2008 to account for one fifth of the global total of aviation-derived $\mathrm{CO}_{2}$ (AngerKraavi and Kohler 2013). In an effort to limit and mitigate the effects of this pollution a range of international, national and local emissions targets have been introduced. The International Air Transport Association (IATA) has set a target of reducing global aviation $\mathrm{CO}_{2}$ by $50 \%$ by 2050 (IATA, 2015) while the European Commission (EC, 2011) aims to reduce European aviation's $\mathrm{CO}_{2}$ emissions by $75 \%$ and $\mathrm{NO}_{x}$ (nitrous oxide) emissions by $90 \%$ relative to the 2000 figure. In the UK, the Government's Committee on Climate Change established a target of stabilising $\mathrm{CO}_{2}$ emissions at 2005 levels by 2050 in order to meet a national target of an $80 \%$ reduction in $\mathrm{CO}_{2}$ relative to 1990 (CCC, 2011). In addition, individual airports, such as London Stansted and East Midlands, have set challenging targets for reducing the carbon intensity of their operation. However, $\mathrm{CO}_{2}$ is just one of a number of pollution species that contribute to anthropogenic climate change and concern is also being articulated about aviation's non- $\mathrm{CO}_{2}$ effects and climate change impact of $\mathrm{NO}_{x}$, carbon monoxide (CO), water vapour and contrails, methane, unburnt hydrocarbons (HCs or particulates) and nonmethane volatile organic compounds.

Unsurprisingly, concentrations of these emissions are often high around the world's major airports. In order to minimise emissions it is imperative that aircraft are handled in the most environmentally efficient manner possible, but a lack of runway capacity means that many aircraft arriving at the world's most capacity constrained airports are required to fly racetrackshaped holding patterns for several minutes before landing which significantly increases the fuel burn and concentrates low altitude emissions over urban areas. A study by Reynolds et al in 2009 revealed that holding and vectoring inbound aircraft was responsible for $25 \%$ of all airborne flight inefficiency in European airspace and that this practice accounted for an average track extension of 14 nautical miles on every intra-European service. Given the adverse environmental implications of airborne delays and the relative paucity of academic research into their effects, this paper studies arrivals during the peak period at London Heathrow and calculates the $\mathrm{CO}_{2}, \mathrm{HC}, \mathrm{CO}$ and $\mathrm{NO}_{x}$ emissions that are generated by aircraft in the hold.

The paper is structured into four sections. Following this introduction, section two reviews the salient literature on aviation, climate change and sustainability and identifies a need to better understand the environmental effects of peak hour air traffic congestion. In order to generate the dataset, an innovative data collection and analysis method was developed and deployed and this is detailed in section three. The results of the research are then presented and discussed in section four in the context of continued concern about air transport and urban climate change.

\section{Literature Review}

The literature addressing commercial aviation's contribution to anthropogenic climate change has a long historical pedigree and the contemporary corpus of work is multidisciplinary, wide ranging and challenging. The crux of the issue is that when jet fuel is burnt in an aircraft's engines a range of gaseous and solid emissions, including carbon dioxide, carbon monoxide, water vapour, nitrous and sulphurous oxides, methane and particulate matter is emitted (Budd and Ryley, 2013). Depending on the altitude and latitude at which they are released, these pollution species can perturb the global climate and degrade local air quality (Popp et al 1999; Zhu et al., 2011). Historically, $\mathrm{CO}_{2}$ has been the focus of much of the research as its 
production is easy to quantify and its environmental effects are relatively easy to determine. However, despite attempts to limit aviation-derived $\mathrm{CO}_{2}$ emissions through a raft of political instruments and industry targets, the difficulties inherent in attempting to attribute responsibility for aircraft emissions in international airspace has meant that aviation has not been included in the Kyoto Protocol and the decision to incorporate aviation within the EU's Emissions Training System has proved highly controversial.

As a consequence, the regulations governing emissions from international aviation remain highly fragmented and challenging to enforce. The UK, in common with many countries, has not been able to resolve the issue of which flights (or portion of flights) it is responsible for, as individual flights may originate and/or terminate overseas, be transporting passengers from multiple countries, be transiting the airspace of several nations for differing lengths of time en-route to its destination, and be operated by an airline based in another country. As such, only domestic aviation is included in the UK's carbon budget (DECC, 2012).

Although scientific uncertainty remains as to likely future $\mathrm{CO}_{2}$ emissions from aviation, a comprehensive review of likely scenarios by Gudmundsson and Anger (2012) found a mean value of 2332 million tonnes of $\mathrm{CO}_{2}$ for the year of 2050. This represents a $143 \%$ increase on the same figure for 2015. At a time when most industries are seeking to reduce their $\mathrm{CO}_{2}$ emissions by as much as $75 \%$ and the Copenhagen accord aims to limit global increases in surface temperatures to no more than $2^{\circ} \mathrm{C}$, the impact of continued growth in aviation emissions will be significant (Bows-Larkin and Anderson, 2013).

In addition to research that examines the global climate impacts of $\mathrm{CO}_{2}$ emissions, studies into the effects of aircraft emissions on local air quality have typically focused on the nearfield effects on the population who live adjacent to an airport or under its final approach paths (Zhu et al., 2011, Garnier et al. 1997). Of critical importance in understanding the impacts of these emissions is identifying the possibilities for reducing them and the relative merits of the different options that are available. The European Commission (2011) anticipated that the introduction of new technology would be the main mechanism for reducing aircraft emissions in the future while the Sustainable Aviation group, a consortium of UK airlines, airports, airframe manufacturers and regulators, identified improvements in aircraft technology, more efficient operations, the use of alternative fuels and carbon trading as being four ways in which $\mathrm{CO}_{2}$ emissions from aviation can be effectively reduced to around half of 2005 levels by 2050 even with an anticipated 150\% growth (Sustainable Aviation 2012).

Aircraft technologies have received considerable attention as a means of reducing aviation's $\mathrm{CO}_{2}$ emissions. New aircraft, including the Boeing 787, feature lighter carbon composite materials and engines with higher bypass ratios. These lighter-weight airframes offer lower fuel consumption and a reduced environmental impact compared to older models. The 787 burns 13\% less fuel than a 767 and 26\% less than a 777 (EASA, 2015). However the delay in uptake of new technology associated with a 20-25 year airframe lifecycle and the high volume of emissions from the manufacturing process mean a full life-cycle analysis would need to be undertaken to truly quantify the net benefit from new equipment. According to Bows-Larkin and Anderson (2013), tackling aviation's climate challenge now will be critical in reducing the severity of improvements required in the future.

Looking instead at the possibilities for operational improvements, Nikoleris et al. (2011) studied the impacts of capacity constraints on taxi time and associated emissions. They concluded that taxiway congestion meant an increase in ground-based fuel burn of $35 \%$. In terms of airspace, some progress has been made by air traffic service providers such as NATS (the air traffic service provider for the UK) to improve the flow of aircraft in their airspace. NATS estimate that their plans to introduce time based separation at Heathrow (in which aircraft are separated by time rather than distance) in early 2015 will cut delays by 
around 20 seconds per arrival while their 'free flight' trial proved that optimising the en-route track of flights conferred significant environmental benefits (NATS, 2014).

Emissions created by aircraft during holding patterns may have an impact on both the surrounding air quality and the global climate. However while emissions from aircraft at ground level are very well understood for their effects on air quality there remains a degree of uncertainty over the impacts associated with aircraft that are at altitude. A study at Heathrow by Faris and ApSimon (2006) found that the NOx contribution from aircraft was often overestimated compared to local road traffic, while Unal et al. (2005) found that airport related emissions tend to be focussed on the local area and diminish rapidly with distance.

The environmental effect of airborne aircraft is an area that requires further research. Current calculations of emissions for whole flights are made by ICAO and EASA (the European Aviation Safety Agency) but all of the existing techniques are limited by the availability of data which is often restricted for reasons of national security or commercial confidentiality). Even where such data are available, variations in climatic conditions, holding, aircraft mass and variations in track distance flown from the filed flightplan can all cause calculated emissions to differ from the actual figure (Jardine 2009). Addressing any of these issues would enable the calculation of emissions to be more accurate and increase understanding of aviation's environmental impact. This paper uses publicly available flight radar data to identify individual flights and determine the tracks and holding patterns they flew.

\section{Method}

This research uses flightpaths plotted by open access online flight radar software to calculate the length of time that aircraft spend in the hold while waiting to land at London Heathrow. This data is then combined with published data on aircraft engine emissions to quantify the pollution these aircraft generate while in the hold.

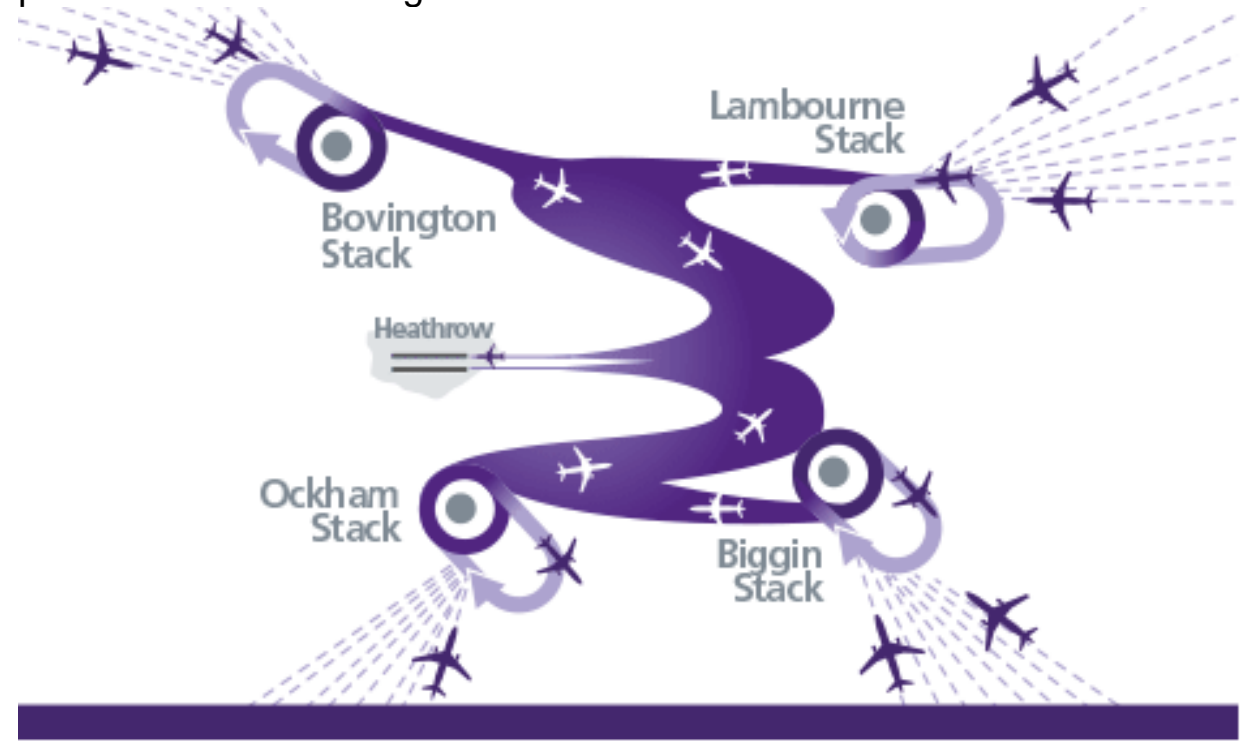

Figure 1 - Diagram of holding patterns at London Heathrow Airport (Heathrow, 2015)

Heathrow represents an ideal case study on the link between capacity constraints and increased emissions, as its two runways are some of the busiest in the world. $57 \%$ of inbound aircraft are obliged to hold before landing (Heathrow Airport Ltd. 2014) and the "snowball" effect that small delays can have on subsequent flights throughout the day are significant. Heathrow currently has four holding stacks - Lambourne, Biggin, Ockham, and 
Bovingdon - which are used to hold inbound aircraft until runway space becomes available for them to land. Lambourne (to the north east) and Biggin (to the south east) in particular are located over the densely populated London Boroughs of Havering and Bromley respectively and the practice of holding obliges aircraft to fly an oval holding pattern at progressively lower altitudes while awaiting their turn to land. The effects of emissions from aircraft holding in these stacks will not only impact the wider climate but also degrade the local air quality over London and the South East. The relationship between the variables and emissions for each arrival as a result of holding is: emissions $(\boldsymbol{k g})=\boldsymbol{e f t}$

Where: $e=$ emissions index $f=$ fuel consumption per engine $(\mathrm{kg}$ per minute $) t=$ time spent in hold (minutes)

\subsection{Flight data}

The published flight schedule for Heathrow was obtained from Innovata's (2015) global airline schedule database. The Heathrow schedule for January 2015 was obtained in rolling hours of 5 minute intervals and the peak arrivals period was identified as occurring on Friday 16th January, between 12:40 and 13:39, when 46 flights were scheduled to arrive. January was used as it was the only month with radar data availability, however Heathrow's seasonality is very flat so this was not an issue. Naturally, there were a small number of flights that were not recorded in the schedule, so the Innovata data was compared with the online live web-based arrivals and departures information provider FlightStats (2015). The "peak" hour (in terms of arriving aircraft per hour) was selected for this analysis as it is the time at which the arrivals system is likely to be under the greatest pressure and aircraft are most likely to have to enter a hold. The hour was carefully checked and analysed to ensure there were no extraordinary circumstances (such as bad weather and knock-on delays) and therefore isolate the cause of delays to a lack of available infrastructure at the arrival airport.

Each flight number from the extracted schedule was entered into the search feature on flightradar24.com and the corresponding flight in the database was found. All salient information about each flight, including position, heading, altitude and ground speed, was obtained. As this research focuses on the approach phase of the flight over London and the South East of England, data availability is good and aircraft position information is triangulated from multiple ground-based radar stations. The duration that each aircraft spends in the hold is timed (to the nearest minute) and recorded. This process was repeated for all the arrivals in the peak hour.

\subsection{Emissions Data}

The data on emissions and fuel consumption was obtained from EASA. They, in conjunction with ICAO, provide detailed statistics on aircraft fuel burn and associated $\mathrm{NO}_{x}, \mathrm{CO}$ and $\mathrm{HCs}$ emissions per minute during various phases of the landing and take-off (LTO) cycle.

However since holding patterns are not normally considered to be part of the standard LTO cycle, the fuel burn and emissions factors used here are associated with the approach phase of the flight and so assume a 30\% thrust setting (the approach thrust level used by EASA). With the exception of the $30 \%$ thrust assumption, variations in the emissions output due to altitude and thrust settings are accounted for in the EASA emissions factors.

The approach used to measure carbon dioxide emissions uses the recognised ICAO (2014) model that burning $1 \mathrm{~kg}$ of fuel creates $3.157 \mathrm{~kg}$ of $\mathrm{CO}_{2}$. Crucially this figure is not affected by altitude, atmospheric conditions or thrust setting. This number is larger than the quantity of 
fuel burned, as the fuel is mainly carbon and the carbon combines with oxygen molecules in the atmosphere to form heavier $\mathrm{CO}_{2}$ particles (Berdy, 2009). In order to equate flights to the engine emissions data, each aircraft's registration serial was obtained from flightradar24.com while the hold duration was being calculated. Each unique aircraft registration was then cross-checked with JP airline fleets directory (Flightglobal, 2013) to ascertain the type and number of engines for each aircraft. Each type of engine has an approach-phase fuel burn estimator in the EASA database. This figure was then multiplied by the number of engines to give the aircraft's total fuel burn per minute. This was then multiplied by the duration that the aircraft spent in the hold to give the volume of fuel burned by the aircraft while in the holding pattern. This fuel burn figure was then multiplied by the engine type's emissions factor (or 3.157 for $\mathrm{CO}_{2}$ ) to give an estimate of the quantity of each pollution species that was emitted by each aircraft while it was in the hold. Supplementary data on seat capacities was obtained from Capstats.com (2015) in order to calculate "per seat" emissions figures and provide a better estimation of the emissions that were generated per passenger. The use of per passenger figures can be mis-leading as changes in the number of passengers can lead to large changes in total emissions regardless of perceived efficiencies on a per passenger basis, however they do allow for simple and coherent comparisons to be made between aircraft of varying size so are used in this paper only where appropriate.

\section{Findings and discussion}

The outputs from each flight in the peak hour are displayed in Table 1. Half of the flights studied entered a hold, slightly below Heathrow's reported 57\% in 2013 (2014). The majority of flights in the sample landed either on time/early or within 20 minutes of the scheduled arrival time (the sole exception landed 34 minutes late). The average aircraft capacity in the study period was 188 seats. Each hold time lasted an average of 6 minutes, creating a total of 138 minutes of aircraft holding time.

Table 1 - Summary of outputs from peak hour

\begin{tabular}{|l|l|l|l|l|l|l|l|}
\hline & Seats & $\begin{array}{l}\text { Hold } \\
(\text { mins) }\end{array}$ & Fuel (kg) & $\mathbf{C O}_{\mathbf{2}}(\mathbf{k g})$ & $\mathbf{H C}(\mathbf{g})$ & $\mathbf{C O}(\mathbf{g})$ & $\mathbf{N o}_{\mathbf{x}}(\mathbf{g})$ \\
\hline Avg. per seat & - & - & 1.18 & 3.70 & 0.098 & 2.19 & 13.2 \\
\hline $\begin{array}{l}\text { Avg. per hold } \\
\text { minute }\end{array}$ & - & - & 73.8 & 232.9 & 6.14 & 137 & 826 \\
\hline $\begin{array}{l}\text { Avg. per } \\
\text { arrival }\end{array}$ & 188 & 3 & 221 & 697 & 18.4 & 412 & 2,478 \\
\hline Avg. per hold & 205 & 6 & 443 & 1,394 & 36.8 & 824 & 4,955 \\
\hline Hour Total & 8,657 & 138 & 10,180 & 32,139 & 847 & 18,961 & 113,968 \\
\hline
\end{tabular}

In terms of emissions, Table 1 shows that the production of $\mathrm{CO}_{2}$ is equal to $233 \mathrm{~kg}$ for every minute in the hold, plus $6 \mathrm{~g}$ of $\mathrm{HC}, 147 \mathrm{~g}$ of $\mathrm{CO}$ and $826 \mathrm{~g}$ of $\mathrm{NO}_{\mathrm{x}}$. Table 2 shows how these emissions were split between the four holds. Although arrivals holding at Biggin had the greatest average hold time, this may be due to individual circumstances on the study day and are not necessarily representative of operations in the Heathrow stacks.

Table 2 - Emissions split by holding pattern

\begin{tabular}{|l|l|l|l|l|l|l|l|}
\hline & $\begin{array}{l}\text { Number } \\
\text { of holds }\end{array}$ & $\begin{array}{l}\text { Hold } \\
\text { Time }\end{array}$ & $\begin{array}{l}\text { Fuel } \\
(\mathbf{k g})\end{array}$ & CO2 (kg) & HC (g) & CO (g) & Nox (g) \\
\hline Biggin & 6 & 49 & 3,225 & 10,184 & 124 & 5,530 & 31,876 \\
\hline
\end{tabular}




\begin{tabular}{|l|l|l|l|l|l|l|l|}
\hline Bovingdon & 5 & 25 & 2,142 & 6,762 & 457 & 4,030 & 20,256 \\
\hline Lambourne & 7 & 28 & 2,075 & 6,549 & 104 & 3,350 & 23,056 \\
\hline Ockham & 5 & 36 & 2,737 & 8,643 & 161 & 6,049 & 38,778 \\
\hline
\end{tabular}

A potential limitation of this study is the fact that it only covered one hour in the year, and that hour may not be representative of the overall picture at Heathrow. With this in mind the results have been cross-checked using the following method. All aircraft and airline combinations at Heathrow in 2013, according to Capstats.com (2015) were assigned engines and emissions in the hold per minute (as per previous method) and every movement in the year was assumed to have the 2013 average (as 2014 data is not currently available) hold delay of 4.7 minutes (Heathrow Airport Ltd. 2014). The results of this exercise are shown in Table 3.

Table 3 - Emissions per hour based on annual assumptions and an 18 hour operating day

\begin{tabular}{|l|l|l|l|l|l|}
\hline & Fuel $\mathbf{( k g )}$ & $\mathbf{C O}_{2} \mathbf{( k g )}$ & $\mathbf{H C}(\mathbf{g})$ & $\mathbf{C O}(\mathbf{g})$ & $\mathbf{N o}_{\mathbf{x}}(\mathbf{g})$ \\
\hline Original & 10,180 & 32,139 & 847 & 18,961 & 113,968 \\
\hline Sense-check & 11,481 & 36,247 & 1,483 & 20,285 & 121,982 \\
\hline \%Difference & $+12.8 \%$ & $+12.8 \%$ & $+75.1 \%$ & $+7.0 \%$ & $+7.0 \%$ \\
\hline
\end{tabular}

The data show that with these assumptions, $\mathrm{CO}_{2}$ emissions are $12-13 \%$ higher than in the study hour. This is to be expected given the higher average annual hold time. The exception is the results for hydrocarbons. The $75 \%$ discrepancy may be due to the comparatively low absolute volume of these emissions and spikes that can be caused by particular aircraft movements (Figure 2).

\subsection{The Study Hour}

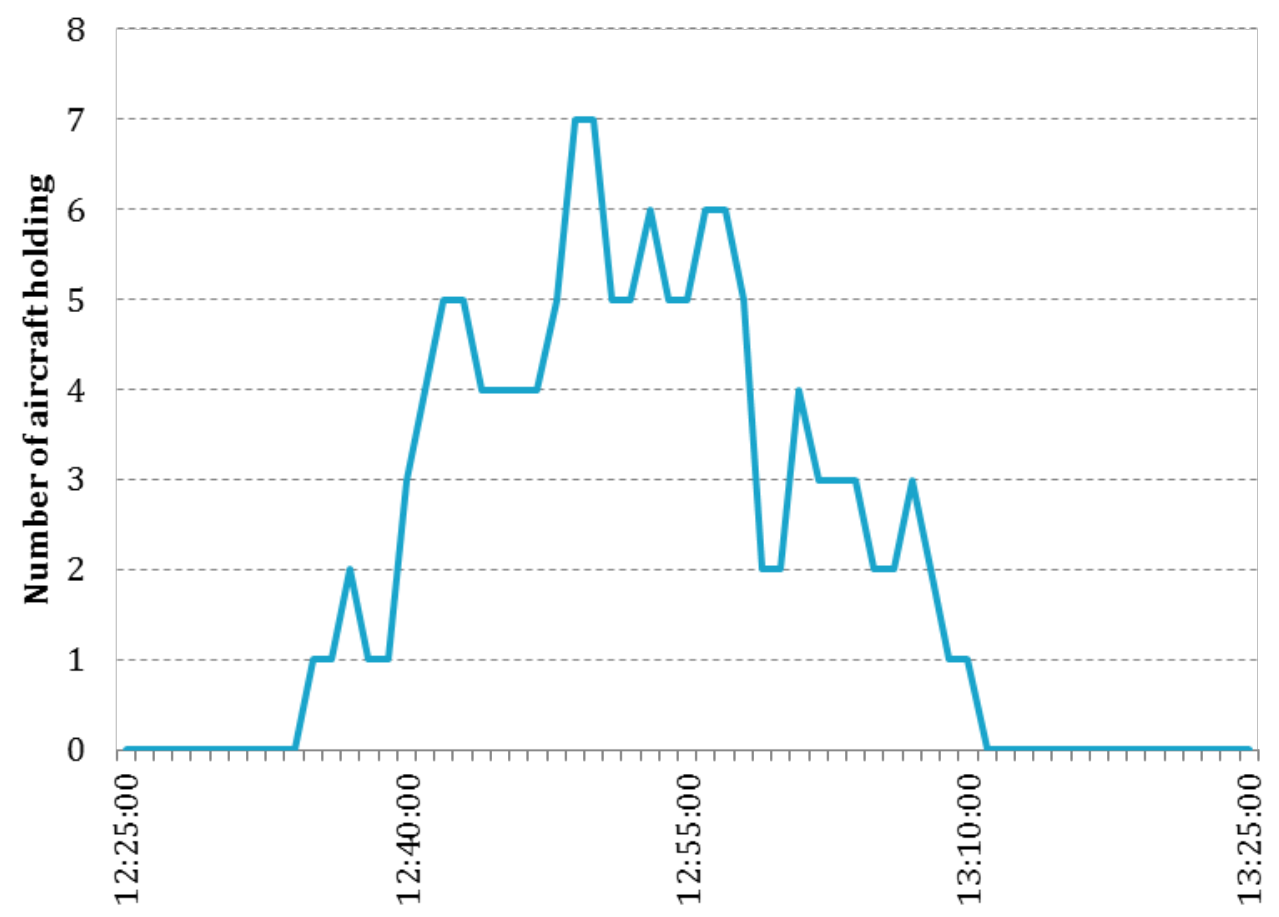

Figure 2 - Holding pattern activity for the study period aircraft 
Figure 2 reveals when the aircraft from the study hour were active in holding patterns (it should be noted that this does not include aircraft from outside the scheduled study hour, which, due to delays in the previous hourly period, may have slipped into the actual study hour). Figure 2 shows that one extended period from 12:35 to 13:10 had a constant stream of aircraft in the hold, which accounts for almost all the aircraft from the study hour that required a holding pattern. The only two other aircraft that were assigned a holding pattern were running early and therefore may have had to wait for a landing slot. The figure shows that stacking aircraft occur in waves - leaving periods of many aircraft holding and periods of no aircraft holding, with very little in between.

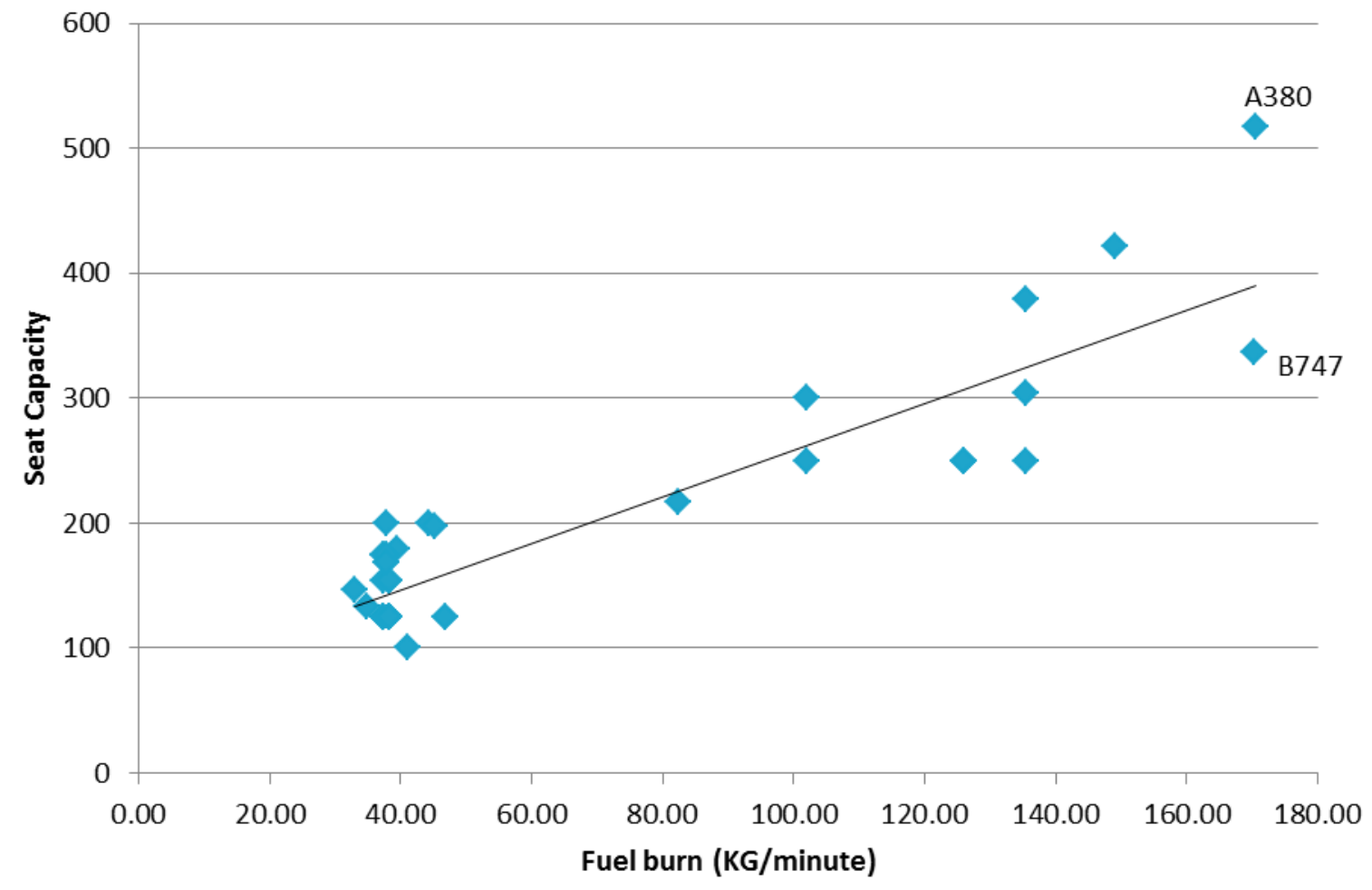

Figure 3 - Fuel burn and seat capacity for the aircraft in the study period

Figure 3 shows the fuel burn per minute output of each flight compared with its seat capacity (including those that did not hold). Examining the use of seat capacity provides an approximation of the passenger numbers on each flight (in general short haul has higher load factors than long haul but the differences are rarely more than 10-20\%). This is a useful metric as although runway capacity is measured in aircraft movements, the demand that creates those movements is in the form of passenger numbers - the use of large but infrequent aircraft (or vice versa) will impact the total emissions generated at the airport.

The majority of short haul flights are flown by 150 to 200 seat $A 320$ and B737 aircraft and fall into the grouping in the lower left, burning between 30 and 50 kilograms of fuel per minute in the hold. As seat capacity increases, the fuel burn increases at a rate of around 0.5 kilograms per minute for each additional seat. Givoni and Rietveld (2010) found that larger aircraft are more pollutant, though on a per seat basis they contribute less to climate change but more to local air pollution. There may be an argument for reducing emissions created in holding patterns by prioritising heavy arrivals, although this is likely to be outweighed by the 
need for capacity-constrained airports to group aircraft by size in order to minimise the impacts of wake turbulence and thereby maximise the airport's runway throughput.

The difference that aircraft technology can make can be seen on the right hand side of Figure 3 with the two highest fuel burning aircraft, a Boeing 747 and an Airbus A380. Whilst the two are both twin deck four jet engine aircraft, the 747 is considerably older and has a lower seat capacity. On a per seat basis, the A380 is more efficient with $0.33 \mathrm{~kg}$ per seat per minute compared to $0.51 \mathrm{~kg}$ for the $747-400$. As emissions are mainly a direct function of fuel burn, this will have implications for the air quality in the surrounding area.

\subsection{Emissions Outputs}

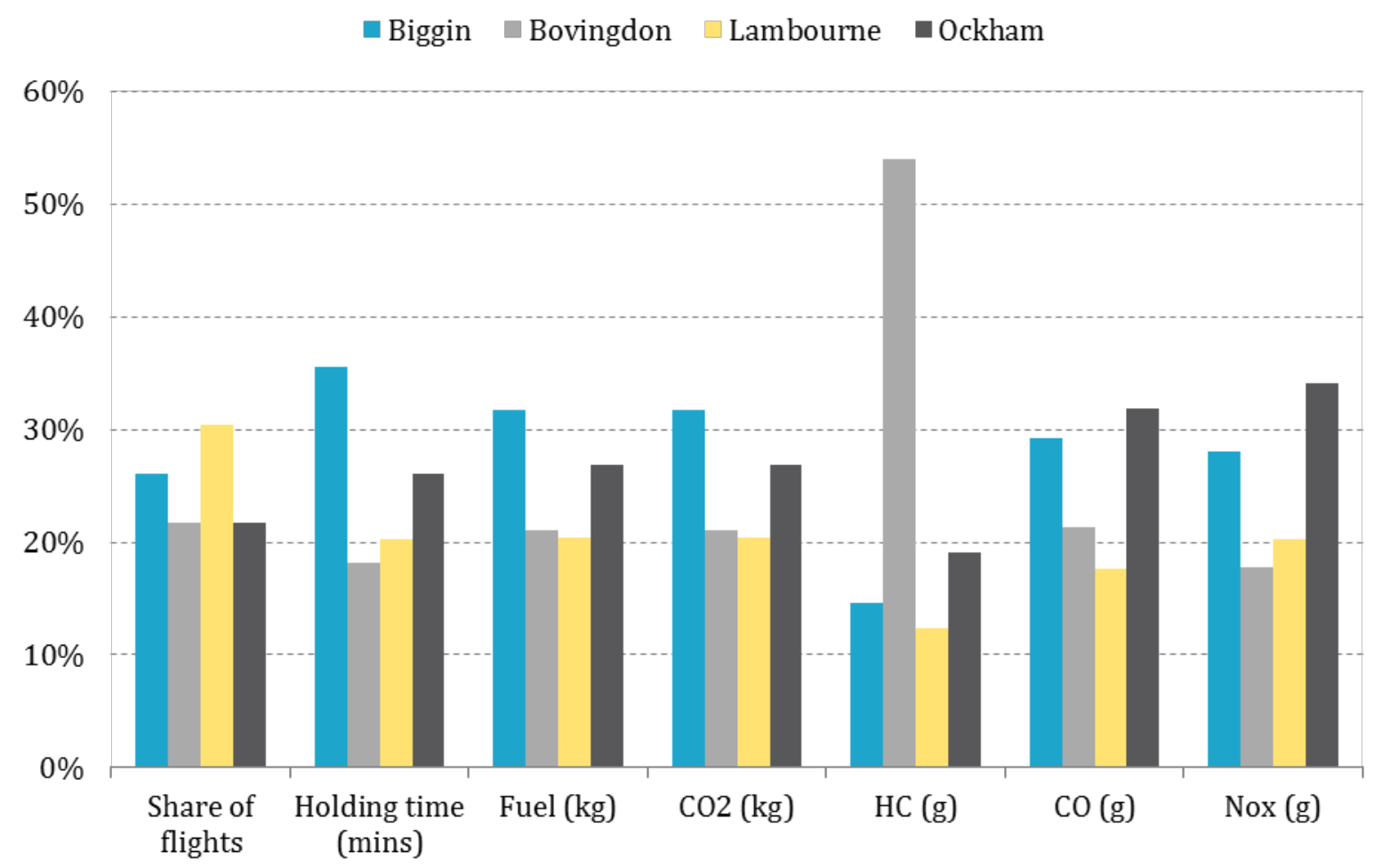

Figure 4 - Holding stacks - Percentage share of flights and emissions

Figure 4 shows the breakdown of the Heathrow holding patterns by share of flights and emissions during the study hour. This shows that the split of flights was fairly even across the airspace, with between five and seven flights using each hold. The spike in HCs experienced in the Bovingdon stack shows the effect that individual aircraft movements can have. In this instance, two Boeing 747-400s (one arriving from Phoenix, the other from San Francisco) were responsible for the majority of these emissions. Given Bovingdon's location to the north west of Heathrow, it is often used by long-haul arrivals from the United States. These larger aircraft have higher thrust requirements, often more engines, and in this particular case the aircraft were older than average (22 and 21 years respectively (Flightglobal, 2013)) - all of which compounds the pollution. 
By contrast, the Lambourne stack experienced more flights, yet its aircraft movements were by five efficient A320/B737 narrow-body aircraft and two comparatively newer wide-body aircraft. The effect of this is that on this particular occasion Lambourne saw the lowest HC emissions of any of the stacks, despite having the most flights. However it should be noted that this is only representative of the study hour, and that all four stacks will experience larger, more polluting aircraft over the course of the day.
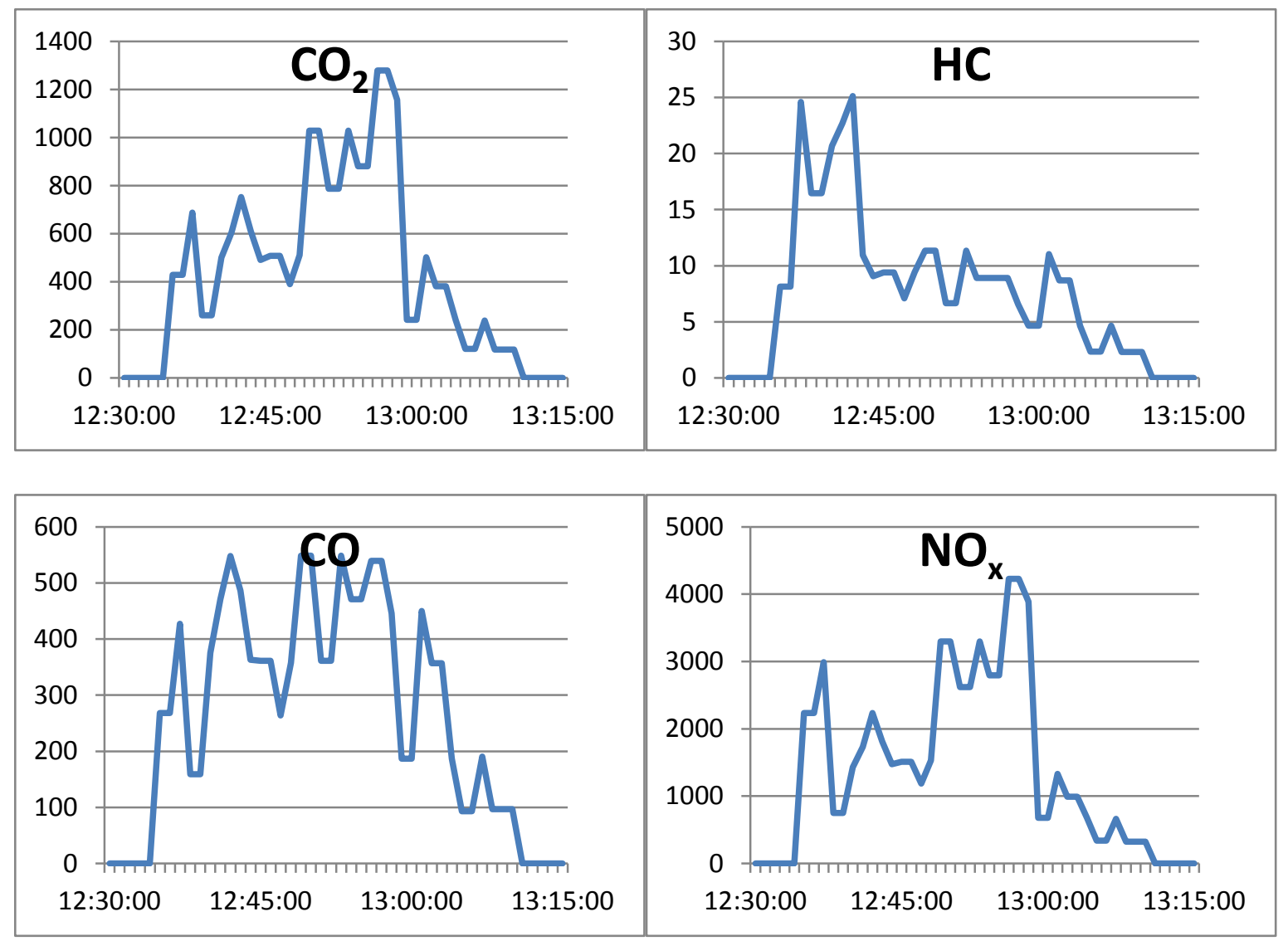

Figure 5 - Emissions from the holding aircraft over time for $\mathrm{CO}_{2}, \mathrm{HC}, \mathrm{NO}_{\mathrm{x}}$ and $\mathrm{CO}$.

Figure 5 reveals the profile of emissions of holding aircraft from the study hour. As can be seen, the peaks for each emission differ and only the carbon monoxide peak corresponds with the peak number of aircraft holding (seven aircraft at 12:49). This suggests that the aircraft and engine types are an equally significant variable as the number of aircraft involved. The profiles for $\mathrm{CO}_{2}$ and $\mathrm{NO}_{x}$ are similar as they are both strongly linked to the fuel burn of the aircraft, where $\mathrm{CO}$ and $\mathrm{HC}$ appear more influenced by individual aircraft types as they are not such a direct function of fuel burn. Figure 6 shows the emissions profiles of six different aircraft that used Heathrow during the study period. 


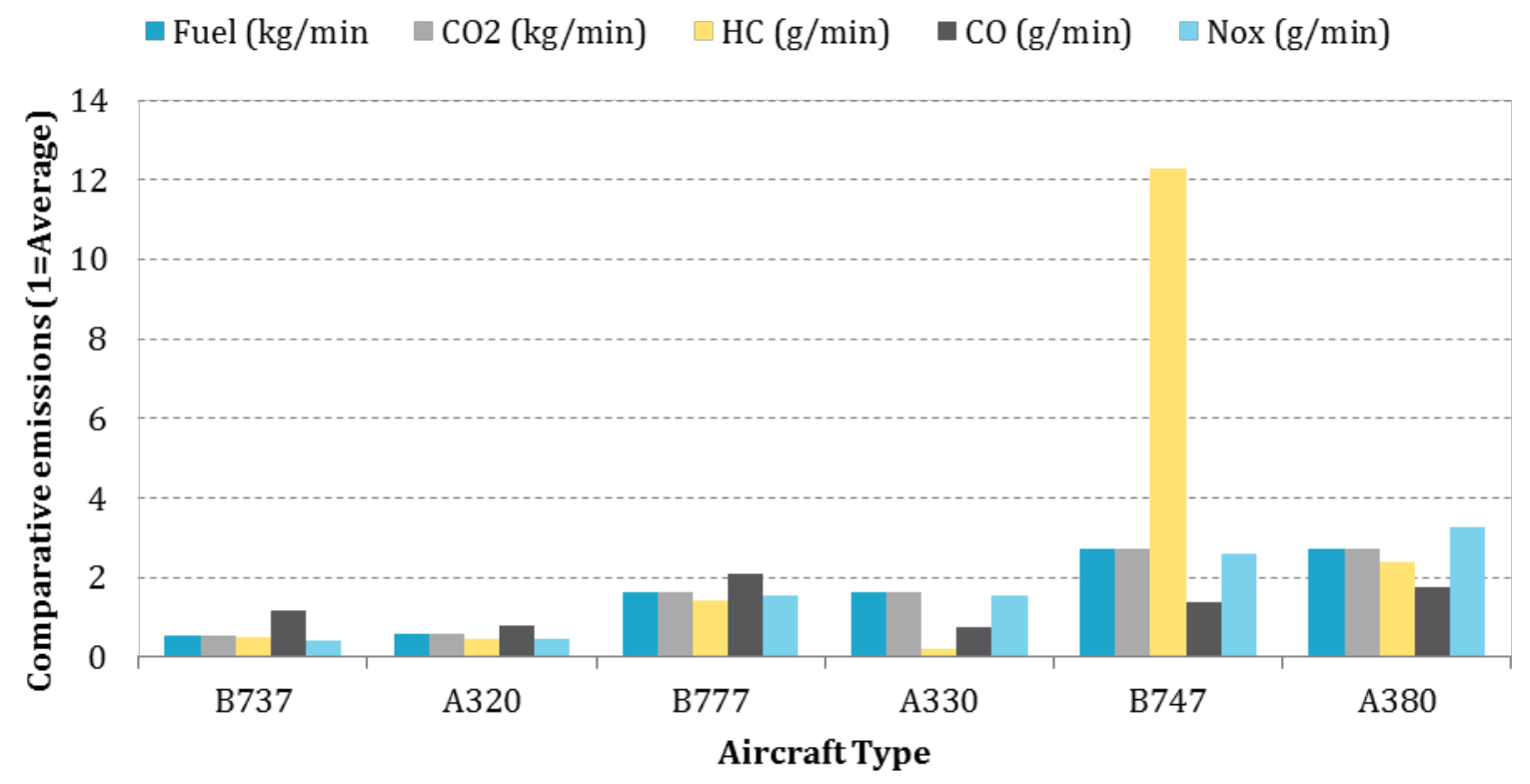

Figure 6 - Comparative emissions of six typical aircraft types at Heathrow

From Figure 6 it can be seen that individual aircraft have a significant influence on the emissions experienced. Leaving aside the 747-400's high hydrocarbon emissions, the difference in emissions from similarly sized aircraft is often significant. This shows that improving aircraft technology is helping to reduce the negative impacts of aviation on the environment, but also that individual airport locations and stacks may experience different profiles of emissions because of the flow of traffic that they handle.

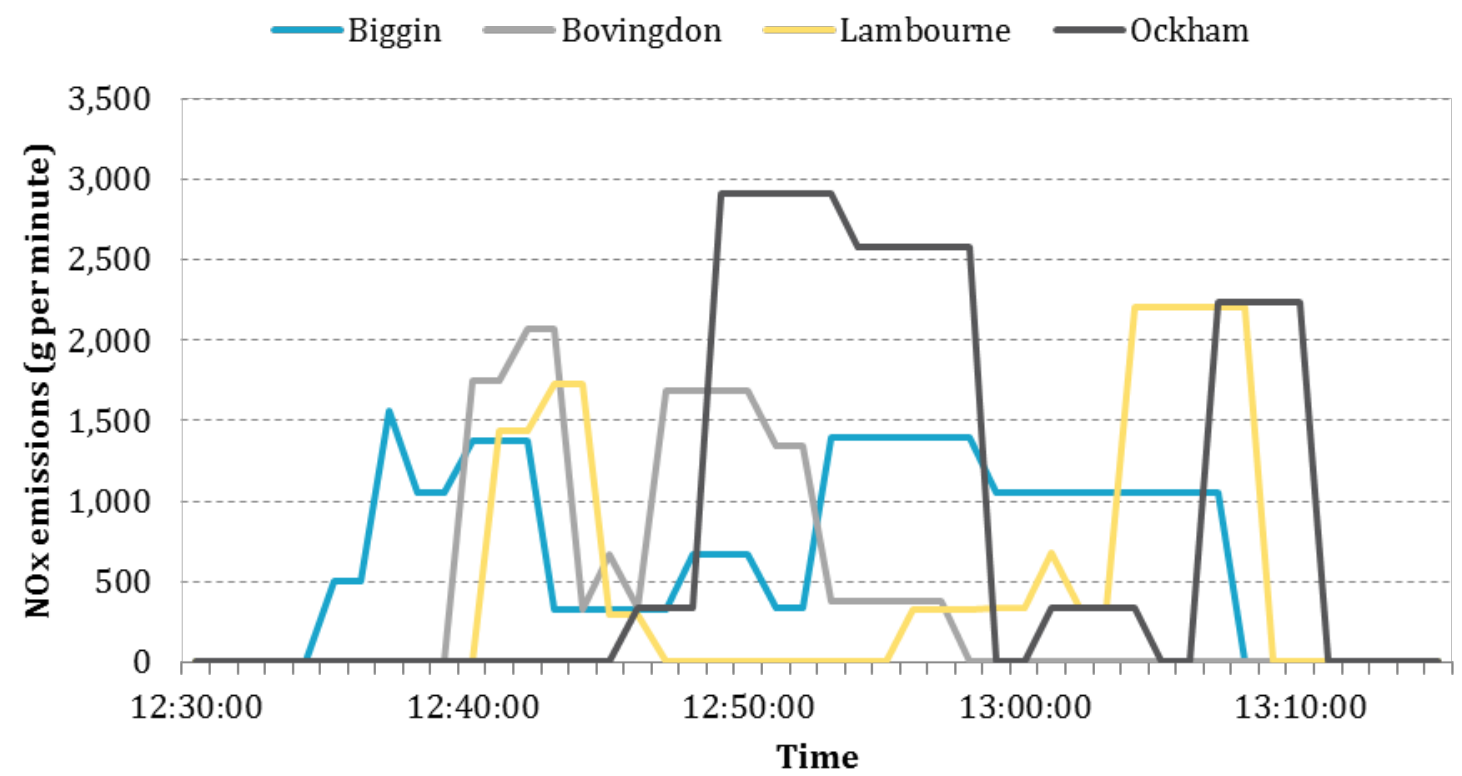

Figure 7 - Holding patterns $-\mathrm{NO}_{x}$ effect of holding aircraft over time 
Figure 7 displays the estimated $\mathrm{NO}_{\mathrm{x}}$ emissions of the holding aircraft by stack. As the holding patterns are over $50 \mathrm{~km}$ apart, it is important to consider these local air quality impacts in their individual locations rather than as a collective. The figure shows that while the split appears to be fairly even across the stacks, and all are experience a peak of at least 2,000 $\mathrm{g} / \mathrm{minute}$, the stack at Ockham is estimated to receive the highest rate of emissions, at 2,913 $\mathrm{g} / \mathrm{minute}$, and this remains as the highest of any stack for 11 minutes.

This shows that the impact of individual stacks is influenced significantly by the flow of aircraft, not only the number of flights, but also the type of aircraft and the length of time they are required to hold. However, since this is a study of just one hour and the flows from individual locations and therefore to individual stacks will change over the course of the day, it is not possible to make conclusions about the overall split of emissions by individual stack at Heathrow.

The aim of this paper has been to quantify the impacts of airport congestion. Using the data from this study, holding aircraft at Heathrow were responsible for $0.075 \mathrm{Mt}$ of $\mathrm{CO}_{2}$. Consequently if all arrivals at Heathrow were able to avoid holding patterns and instead land immediately, this would equate to a saving of $0.2 \%$ on UK aviation's total emissions - a small but certainly not insignificant amount.

\section{Conclusions}

This research has quantified the emissions created by aircraft holding in stacks waiting to land at London Heathrow, one of the most congested airports in the world. It has shown that, during one peak hour in January 2015, aircraft holding in stacks were responsible for over ten tonnes of carbon dioxide emissions, 847 grams of hydrocarbons, $1 \mathrm{~kg}$ of carbon monoxide, and around $114 \mathrm{~kg}$ of nitrous oxides. The type of aircraft has a significant impact on the quantity of emissions; improving technologies may help alleviate some of the problem and further analysis could better quantify the costs and benefits of prioritising the landing of large aircraft in the event of significant airborne delays.

In terms of local air quality, Heathrow Airport focuses on reducing local $\mathrm{NO}_{x}$ emissions (Heathrow Airport, 2011). Although Heathrow does not directly measure the emissions generated by holds, this paper has revealed that figure to be around 801 tonnes of $\mathrm{NO}_{\mathrm{x}}$ per year, which is equal to around half of the 1,637 tonnes of $\mathrm{NO}_{x}$ emitted by aircraft on the ground, and is therefore significant. In terms of $\mathrm{CO}_{2}$, the quantities being emitted are equivalent to over $1 \mathrm{~kg}$ per passenger seat per minute, and at Heathrow each arrival averages somewhere between 3 and 5 minutes of time in the hold. The effects on the environment are such Heathrow bound flights burn an average of $0.6 \%$ more fuel because of holding patterns at the airport. This creates an interesting counter-point to the restricting of airport capacity as an environmental policy, however the impacts discussed here would still be fairly minimal compared to the emissions created from additional flights.

Holding patterns at capacity constrained airports like Heathrow have significant impact on emissions, averaging $0.6 \%$ extra fuel burn and $\mathrm{CO} 2$ per flight. The exact emissions vary greatly by aircraft type, and the frequency and duration of these holding patterns can often be significant during periods of high demand for runway usage. Further research could seek to address how the emissions from these aircraft dissipate between the holding patterns and the ground, and how operations can be streamlined to reduce the delays associated with runway capacity constraints.

\section{Acknowledgements}


The authors would like to thank Professor Maria Attard and her colleagues at the University of Malta for hosting the urban transport and climate change conference at which this paper was originally presented. This research forms part of an Engineering Doctorate which is funded jointly by the EPSRC and RDC Aviation Ltd (parent of Aviation Economics) and administered by the Centre for Innovative Construction Engineering (CICE) at Loughborough University. Special thanks are due to Tim Coombs and Fazrul Roslan at Aviation Economics for their assistance.

\section{References}

Airports Commission (2013) Airports Commission: Interim Report [online] available from https://www.gov.uk/government/uploads/system/uploads/attachment data/file/271231 lairports-commission-interim-report.pdf [19th February 2015]

Barrett, S.R.H., Britter, R.E., Waitz, I.A. (2010) 'Global Mortality Attributable to Aircraft Cruise Emissions'. Environmental Science and Technology 44, 7736-7742

Berdy, P. (2009) 'Environmental Cooldown'. Ascend 2008 (2), 54-57

Bows-Larkin, A., and Anderson, A. (2013) 'Carbon budgets for aviation or gamble with our future?'. In Sustainable Aviation Futures. ed. by Budd, L., Griggs, S., Howarth, D. Bingley: Emerald Group Publishing Ltd., 65-84

Capstats.com (2015) Capstats.com - Global Airlines Schedule Data [online] available from $<$ www.capstats.com. [19th February 2015]

CCC (2014) Factsheet: Aviation [online] available from < http://www.theccc.org.uk/wpcontent/uploads/2013/03/Aviation-factsheet-2014.pdf> [23 ${ }^{\text {rd }}$ February 2015]

Committee on Climate Change (2011) Meeting the UK aviation target - options for reducing emissions to 2050 [online] available from:

<http://archive.theccc.org.uk/aws2/Aviation\%20Report\%2009/21667B\%20CCC\%20A viation\%20AW\%20COMP\%20v8.pdf>

DECC (2012) International aviation and shipping emissions and the UK's carbon budgets and 2050 target [online] available from < https://www.gov.uk/government/uploads/system/uploads/attachment data/file/65686/ 7334-int-aviation-shipping-emissions-carb-budg.pdf $>$ [23 ${ }^{\text {rd }}$ February 2015]

EASA (2015) ICAO Aircraft Engine Emissions Databank [online] available from: < http://www.easa.europa.eu/document-library/icao-aircraft-engine-emissionsdatabank $>\left[25^{\text {th }}\right.$ January 2015]

European Commission (2011) Flghtpath 2050 - Europe's vision for aviation [online] available from: http://ec.europa.eu/transport/modes/air/doc/flightpath2050.pdf $\left[16^{\text {th }}\right.$ February 2015]

Farias, F., ApSimon, H. (2006) 'Relative contributions from traffic and aircraft NOx emissions to exposure in West London'. Environmental Modelling and Software 21, 477-485

FlightStats (2015) London Heathrow Airport Arrivals [online] available from http://www.flightstats.com/ [16 ${ }^{\text {th }}$ January 2015]

Flightglobal (2013) JP Airline Fleets - World Airline Fleet Directory. Sutton: Flightglobal

Flightradar24.com (2015), flightradar24.com - Live flight tracker [online] available from: www.flightradar24.com [16 ${ }^{\text {th }}$ February 2015]

Garnier, F., Baudoin, C., Woods, P., Louisnard, N. (1997) 'Engine emission alteration in the near field of an aircraft'. Atmospheric Environment 31(12) 1767-1781

Giles, J. (2005) 'Europe set for tough debate on curbing aircraft emissions'. Nature 436, 764765

Givoni, M., Rietveld, P. (2010). 'The environmental implications of airlines' choice of aircraft size'. Journal of Air Transport Management 16. 159-167

Gudmundsson, S.V., Anger, A. (2012) 'Global carbon dioxide emissions scenarios for aviation derived from IPCC storylines: A meta-analysis'. Transportation Research Part D 17 (2012), 61-65 
Heathrow Airport (2011) Heathrow Air Quality Strategy 2011-2020 [online] Available from: http://www.heathrowairport.com/static/Heathrow/Downloads/PDF/air-qualitystrategy LHR.pdf [26th February 2015]

Heathrow Airport Ltd. (2013) Airports Commission: Long term hub capacity options Heathrow Airport Ltd. response [online] available from http://www.heathrowairport.com/static/HeathrowAboutUs/Downloads/PDF/long-termhub-capacity-options LHR.pdf [25th February 2015]

Heathrow Airport Ltd. (2014) Flight Performance Annual Report 2013 [online] Available from $<$ http://www.heathrowairport.com/static/Heathrow_Noise/Downloads/PDF/FlightPerformance-Report-2013.pdf> [16th February 2015]

Heathrow Airport Ltd. (2015) Arrival Flight Paths [online] available from: <http://www.heathrowairport.com/noise/heathrow-operations/arrival-flight-paths> [19th February 2015]

IATA (2014) Climate Change [online] available from http://www.iata.org/policy/environment/Pages/climate-change.aspx $\left[19^{\text {th }}\right.$ February 2015]

IATA (2015) Aviation and Climate Change - Pathway to Carbon Neutral growth by 2020 [online] available from:

$<$ https://www.iata.org/whatwedo/environment/Documents/aviation-climatechangepathway-to2020.pdf>

ICAO (2014) ICAO Carbon Emissions Calculator Methodology [online] available from: http://www.icao.int/environmentalprotection/CarbonOffset/Documents/Methodology\%20ICAO\%20Carbon\%20Calculato r v7-2014.pdf. [16 ${ }^{\text {th }}$ February 2015]

Innovata (2015) Flight Schedules Database

IPCC (1999) IPCC special report - Aviation and the Global Atmosphere [online] available from: https://www.ipcc.ch/pdf/special-reports/spm/av-en.pdf [accessed 23rd February 2015]

Jardine, C.N. (2009) Calculating the Carbon Dioxide Emissions of flights [online] available from: http://www.eci.ox.ac.uk/research/energy/downloads/jardine09carboninflights.pdf $\left[16^{\text {th }}\right.$ February 2015]

Lee, D.S., Fahey, D.W., Forster, P.M., Newton, P.J., Wit, R.C.N., Lim, L.L., Owen, B., Sausen, R. (2009) 'Aviation and Global Climate Change in the $21^{\text {st }}$ Century'. Atmospheric Environment 43, 3520-3537

NATS (2014) Time based separation at Heathrow a world first [online] available from < http://www.nats.aero/newsbrief/time-based-separation-heathrow-world-first/> $\left[25^{\text {th }}\right.$ February 2015]

Nikoleris, T., Gupta, G., Kistler, M. (2011) 'Detailed estimation of fuel consumption and emissions during aircraft taxi operations at Dallas/Fort Worth International Airport'. Transportation Research Part D: Transport and Environment 16(4) 302-308

Popp, P.J., Bishop, G.A., Stedman, D.H. (1999) 'Method for Commercial Aircraft Nitric Oxide Emission Measurements' Environmental Science \& Technology 33, 1542-1544

Reynolds T, Gilingwater D, Caves R and Budd L (2009) 'Climate related air traffic management: Final report. Assessing the role of air traffic management in reducing the environmental effects of aviation' Manchester, OMEGA

Sustainable Aviation (2012) Sustainable Aviation CO2 Roadmap 2012 [online] available at: http://www.sustainableaviation.co.uk/wp-content/uploads/SA-CO2-Road-Map-fullreport-280212.pdf [16 ${ }^{\text {th }}$ February 2015]

Unal, A., Hu, Y., Chang, M.E., Talat Odman, M., Russell, A.G. (2005), 'Airport related emissions and impacts on air quality: Application to the Atlanta International Airport', Atmospheric Environment 39, 5787-5798

Yu, K.N., Cheung, Y.P., Cheung, T., Henry, R.C. (2004) 'Identifying the impact of large urban airports on local air quality by nonparametric regression'. Atmospheric Environment 38, 4501-4507 
Zhu, Y., Fanning, E., Yu, R.C., Zhang, Q., Froines, J.R. (2011) 'Aircraft emissions and local air quality impacts from takeoff activities at a large International Airport'. Atmospheric Environment 45(36), 6526-6533 